Article

\title{
Fresh Frozen Allogeneic Bone Block in Maxillary Sinus Floor Elevation: Histomorphometric Analysis of a Bone Specimen Retrieved 15 Years after Grafting Procedure
}

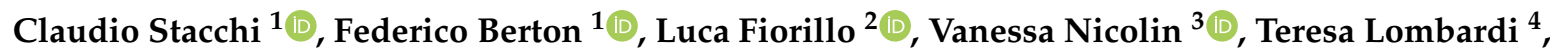 \\ Marco Cicciù ${ }^{2, *(1)}$ and Roberto Di Lenarda ${ }^{1}$ \\ 1 Department of Medical, Surgical and Health Sciences, Trieste University, 34100 TS Trieste, Italy; \\ claudio@stacchi.it (C.S.); fberton@units.it (F.B.); rdilenarda@units.it (R.D.L.) \\ 2 Department of Biomedical and Dental Sciences and Morphological and Functional Imaging, \\ Messina University, 98100 ME Messina, Italy; lfiorillo@unime.it \\ 3 Bone Lab, Department of Medical, Surgical and Health Sciences, Trieste University, 34100 TS Trieste, Italy; \\ nicolin@units.it \\ 4 Private Practice, 87011 CS Cassano allo Ionio, Italy; drteresalombardi@libero.it \\ * Correspondence: mcicciu@unime.it; Tel.: +39-0902-216-920; Fax: +39-0902-216-921
}

Received: 16 February 2019; Accepted: 13 March 2019; Published: 17 March 2019

check for updates

\begin{abstract}
Nowadays implant-prosthetic rehabilitations are one of the best solutions for rehabilitating our patients. These allow obtaining rehabilitations with optimal functional and aesthetic performances. Often patients, who undergo implant-prosthetic therapy, have the conditions of edentulias, single or multiple, that have been going on for some time. This, according to the literature, produces resorption of the alveolar bone, a process that is complicated in the posterior area of the upper arch by a pneumatization of the maxillary sinuses. The loss of vertical height, so that the implant fixtures can be inserted, requires a maneuver called maxillary sinus floor elevation. This procedure, now safely performed with piezoelectric instruments, allows increasing bone height through bone grafting. In this study, the tissue obtained from a patient, after 15 years from the intervention, was evaluated by histological and SEM analyses. The bone healing in the patient has led to a perfect integration between the patient's bone and the fresh frozen allograft used, however still present and detectable after 15 years.
\end{abstract}

Keywords: bone block; sinus floor elevation; bone graft; piezoelectric; PBS

\section{Introduction}

Implant-supported rehabilitation of the atrophic posterior maxilla generally finds the maxillary sinus both as a boundary and an opportunity. In fact, bone regeneration in the Highmore antrum presents favorable conditions for an optimal bone-graft integration: a secluded defect surrounded by osteogenic surfaces, isolated from the occlusal forces and from the oral microbiological environment. Since its introduction in the early 1980s [1,2], the surgical approach to access maxillary sinus and its clinical indications have greatly evolved. Nowadays, lateral sinus augmentation can be safely performed with piezoelectric instrumentation [3-5], and reliable alternatives (transcrestal approach, short implants) are available in selected cases [6-8].

Even if, in sinus floor elevation, autogenous bone is still the better material in terms of osteogenicity, osteoconduction, osteoinduction, and osteointegration, a robust body of evidence showed comparable results using an allograft, alloplastic, xenograft, and blood clot alone in 
the outcomes of this surgical technique [9-14]. However, limited conclusions should be drawn on bone grafting outcomes, when considering implant survival rate as the principal variable. Histomorphometric analysis should be considered as the gold standard measure to test the performance of different biomaterials, taking also in consideration that recent studies showed significant differences in terms of graft integration and substitution according to several variables, such as sinus buccolingual width, residual bone quantity, sinus walls thickness, membrane detachment from sinus walls, and overall graft volume [15-20]. The anatomy of the posterior upper jaws, if edentulous, is clinically considered to be a difficult area for the dental implants positioning due to the atrophic ridge surgical management, the deficient bone quality, and sinus pneumatization. In the last decades, with the development implant surface treatment, newly bone graft materials, and less invasive surgical techniques, the sinus lift surgery by crestal or lateral approach has been accepted as a common predictable treatment procedure in dentistry [9-20]. Several published papers investigated the sinus lift surgical technique focusing on long-term absorption of the placed autogenous bone graft materials or mixed with other bone substitutes material in order to evaluate the bone graft residual at the time of dental implants placement. Retrospective studies at 60 months revealed how, even the surgical procedure works with the long- term dental implant stability and no signs of inflammation of the final prosthodontics crown restored over the dental implants, the residual of the applied biomaterials could be presented related to the kind of material used. However, today, the autogenous bone graft represents the gold standard for this kind of surgical procedure [18-22].

Moreover, the behavior and the modifications of the regenerated bone still remain unclear. Only a few isolated reports described the histologic characteristics of biopsies retrieved from augmented sinuses with long-term follow-up. Generally, the newly-formed bone surrounding and in contact with the biomaterial, which after 6 months of healing is mainly immature woven bone, with time is replaced by mature lamellar bone bridging the graft particles. Xenografts are the most investigated biomaterials: up to 14 years, inorganic bovine bone showed good osteoconnectivity between the grafting particles and the newly formed bone, without signs of inflammation [21-23]. This bone substitute is hardly resorbed by the osteoclasts and is still present with different percentages in all the biopsies taken at different time points in the various studies. Galindo-Moreno and coworkers [24] did not demonstrate significant differences in vital bone and residual graft percentages in biopsies harvested six months, three years, and seven years after maxillary augmentation with inorganic bovine bone. Similarly, Di Stefano and coworkers [25], evaluating three cohorts of patients at different healing intervals (three to five months; six to eight months; nine to twelve months), suggested that implants can be safely inserted during all the aforementioned periods because new bone formation occurs mainly at an early time after grafting procedure.

Nevertheless, to the authors' knowledge, no histologic evidence exists in the literature regarding the fate of bone allograft when used in maxillary sinus floor elevation after the common healing time after surgery (six to nine months). The present study reported the histomorphometric evaluation of a bone specimen retrieved 15 years after sinus augmentation performed by using a cortico-cancellous block of fresh frozen bone allograft.

\section{Materials and Methods}

A Caucasian 50 years old healthy woman, non-smoker, underwent maxillary sinus floor elevation with the lateral approach in 2003. The patient was in the Applegate-Kennedy class II situation, presenting upper left partial edentulism distally to the second premolar and 2-4 $\mathrm{mm}$ of crestal bone height below the maxillary sinus floor in the planned implant sites. The outpatient procedure was held by one of the authors (CS) under local anesthesia: after raising a full thickness trapezoidal flap, the antrostomy was performed by using a piezoelectric device (Piezosurgery II, Mectron, Carasco, Italy), and the Schneiderian membrane was carefully elevated with manual instruments. After checking the sinus membrane integrity with Valsalva maneuver, a monocortical-cancellous block of fresh frozen allogeneic bone from the iliac crest (FFB) was shaped, positioned in contact with the sinus floor, 
and stabilized with two screws (Figure 1). A resorbable collagen membrane (BioGide, Geistlich, Wolhusen, Switzerland) was then placed over the antrostomy, and the flap was sutured with primary intention [26]. After nine months of uneventful healing, two implants $(4.0 \times 13 \mathrm{~mm}$; Astra Tech AB, Mölndal, Sweden) were inserted in first and second molar positions, respectively, and loaded with cemented splinted ceramic crowns after additional five months. After 14 years of function, the two implants failed due to untreatable peri-implantitis and were retrieved by the same surgeon (CS), by using a counter-torque ratchet. After two months of healing, a new implant bed was prepared between the sites of the two removed fixtures by using a 3-mm trephine bur, and a new implant was placed in the biopsy site $(5.0 \times 7 \mathrm{~mm}$; Zimmer Biomet Dental, Palm Beach Gardens, FL, USA) (Figure 2).

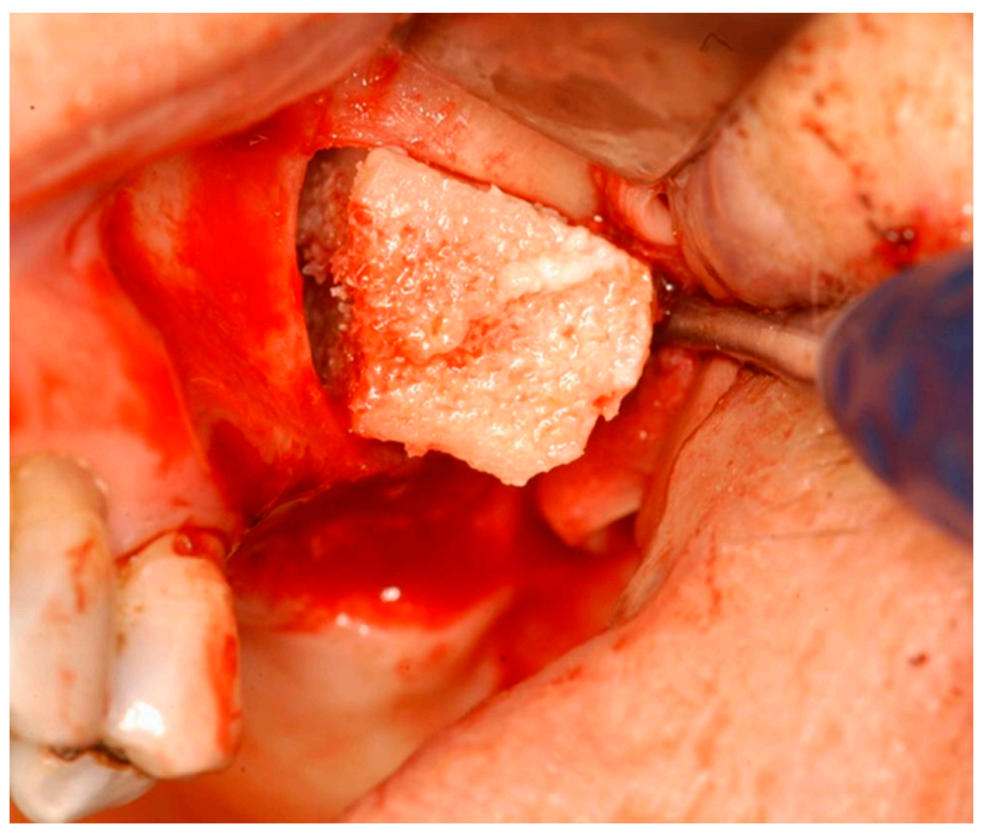

Figure 1. A monocortical-cancellous block of fresh frozen allogeneic bone from the iliac crest (FFB) was inserted into the sinus cavity after opening a lateral window and carefully detaching the Schneiderian membrane.

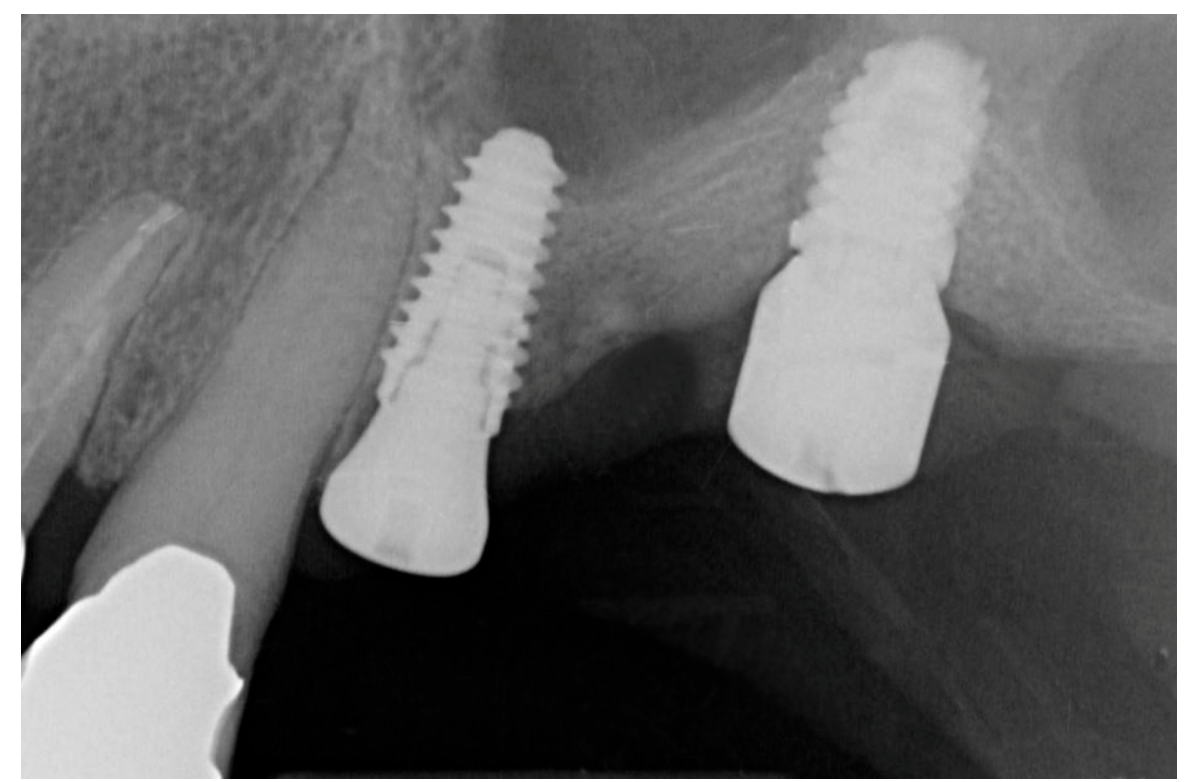

Figure 2. A new implant was inserted in the bed prepared by 3-mm trephine. 


\subsection{Specimen Processing and Histologic Analysis}

Immediately after retrieval, the bone specimen was gently pushed out from the trephine bur, washed under cold sterile 5\% glucose solution to remove blood remnants, and fixed in $10 \%$ buffered formalin solution for two days. The bone biopsy was then dehydrated in an ascending series of alcohol rinses and embedded in a methacrylate resin (Technovit 7200 VLC, Kulzer, Wehrheim, Germany) [27]. After 12 days of polymerization, the specimen was sectioned along its longitudinal axis with a high-precision carburundum disk at $50 \mu \mathrm{M}$ and then ground down to about $30 \pm 10 \mu \mathrm{M}$ under running water with a series of polishing discs. The slides were then mounted and stained with acid fuchsine-toluidine blue and von Kossa staining. The slides were observed with a digital camera (Moticam 5.0, Motic Microscopy, Kowloon, Hong Kong, China) directly applied on a normal transmitted light microscope (Biostar B3, Exacta Optech, San Prospero, Italy) at $100 \times$ and $400 \times$ global magnification and with oil lens immersion under $400 \times$ magnification. Bone histomorphometric analysis was performed using Photoshop CC (Adobe Systems, San Jose, CA, USA) and BoneJ (www.imageJ.org), evaluating the following measures: bone volume/total volume (BV/TV), native bone (NB), newly formed bone (NFB), residual graft (RG), non-mineralized tissue (NMT). Other static measures were performed, such as bone-particle conductivity index (BPCi), defined as BPCi $=\mathrm{LC} / \mathrm{PG}$ in which LC is the sum of contact lengths between new bone and bone graft particles, and PG is the sum of perimeters of bone graft particles; trabecular thickness (Tb.Th) and trabecular spacing (Tb.Sp), as useful data for morphological and metabolic bone behavior.

\subsection{Scanning Electron Microscopy (SEM)}

The acid fuchsine-toluidine blue stained slide was chosen for SEM analysis. Briefly, the slide was abraded using 2000 grit diamond and polishing disks to eliminate the residual staining. Thereafter, the slide underwent another ascending series of alcohol rinses, was dried and finally treated with carbon ion coating for SEM imaging with secondary electrons and EDX (Energy Dispersive X-ray) analysis. This method of electronic investigation is used in the dental field for the evaluation of hard and soft tissues, but it is not only a routine in clinical practice but also in dental biosciences [27,28].

\section{Results}

The histomorphometric analysis highlighted residual graft particles, even if completely surrounded by newly formed bone, thanks to the presence of empty osteocyte lacunae. The native bone of the residual crest, characterized by fewer marrow spaces, was in deep connection with the regenerated bone. No inflammatory cells were found. The global morphology of the specimen reflected a low-quality D4 native bone (Figure 3).

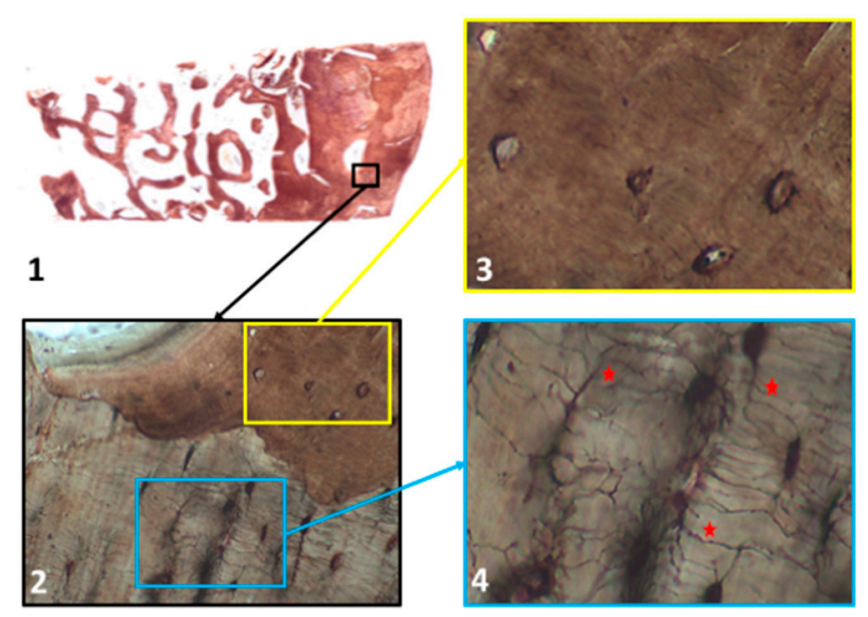

Figure 3. Undecalcified section of the bone specimen retrieved from the maxillary sinus. (1) whole sample; (2) detail of NFB inhabited by dendritic-like osteocytes with cell-to-cell contacts (red stars in 
picture 4); (3) RG with empty osteocyte lacunae, the absence of dendritic-like cells; (4) NFB with osteocytes. Von Kossa staining, resin inclusion, $40 \times$ and $400 \times$ total magnification. NFB, newly-formed bone; RG, residual graft.

Lamellar bone with primary and secondary osteons could be found together with cemented lines. The normal population of osteocytes and osteoblasts and absence of osteoclasts reflected the physiological behavior of maxillary bone. An interesting finding was a possible pseudo-dendritical activity of some osteocytes found on the boundary between old and new bone (Figure 4).
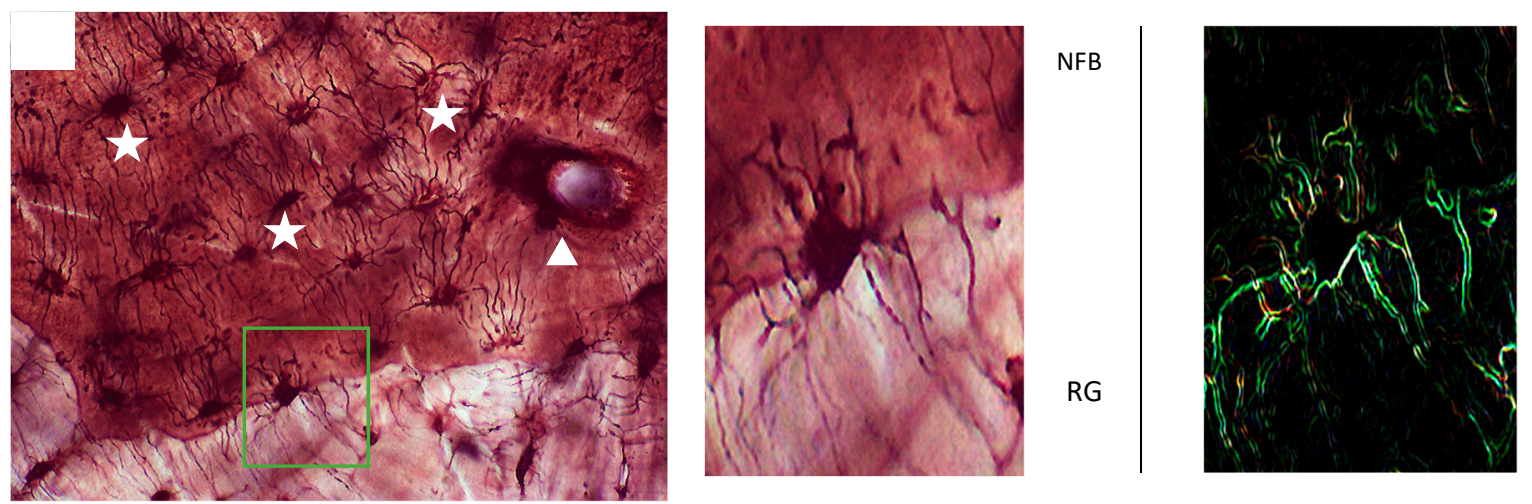

Figure 4. Undecalcified section of lamellar bone (details of Figure 3) (1) interface between NFB and RG (below). Note the presence of a primary osteon (arrowheads) and osteocytes (stars); (2) close-up of an osteocyte in the interface between NFB and RG, with pseudo-dendritical activity towards RG;

(3) pseudo-dendritical activity has been highlighted by post-processing software. Von Kossa staining, resin inclusion, $40 \times$ and $400 \times$ total magnification. NFB, newly-formed bone; RG, residual graft.

Histomorphometric analysis showed $40.8 \%$ of vital bone, $15.4 \%$ of residual graft particles, and $43.8 \%$ of marrow spaces. BPCi of the residual graft particles was $47.5 \%$; Tb. Th showed an average of $0.34 \mathrm{~mm} \pm 0.21$ with a maximum value of $0.76 \mathrm{~mm}$; Tb.Sp showed an average of $0.2 \mathrm{~mm} \pm 0.2 \mathrm{with}$ a maximum value of $0.44 \mathrm{~mm}$ (Figure 5).
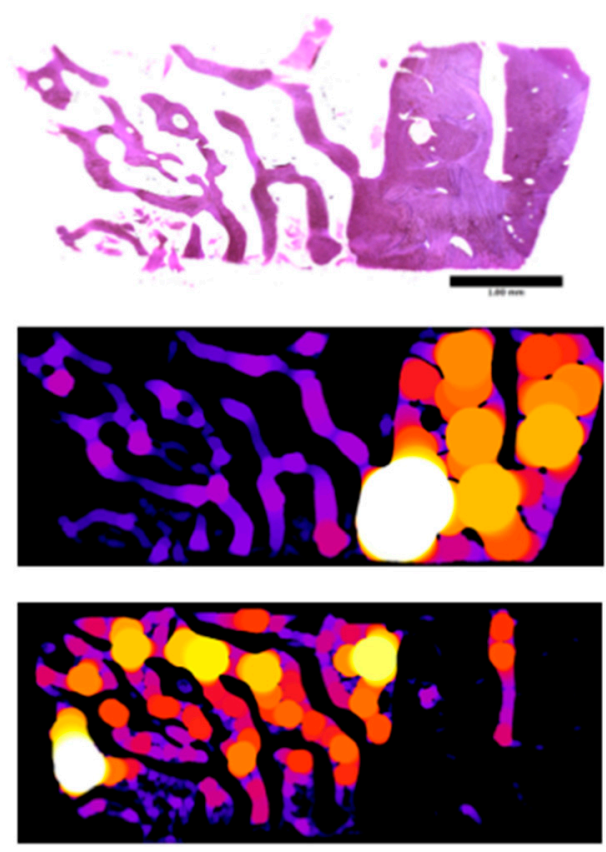

Figure 5. From top to bottom: undecalcified section of the bone specimen, acid fuchsine-toluidine blue staining, 40× magnification; graphic appearance of trabecular thickness index (Tb.Th) obtained with 
the BoneJ plug-in of ImageJ software, which generates circles inside trabeculae; graphic appearance of trabecular spacing index (Tb.Sp) obtained with the BoneJ plug-in of ImageJ software, which generates circles inside marrow spaces.

From secondary electrons SEM analysis, the mineralized tissues appeared homogeneous without any sign of gap between RG and NFB; only a slight discoloration between the parts could be found, according to the same findings obtained by an optical microscope (Figure 6). EDX analysis showed the same content of $\mathrm{Ca}++$ and $\mathrm{P}++$ and the same ratio between the two elements when analyzing three couples of adjacent portions of RG and NFB (Figure 7).

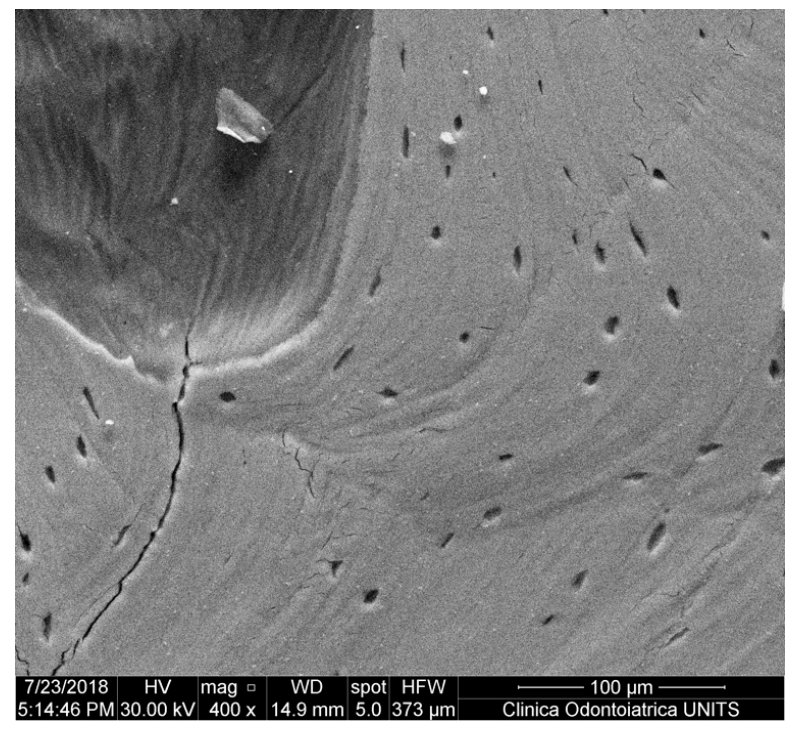

Figure 6. Secondary electrons SEM image of the interface between NFB (upper-right), RG (lower), and MS (upper-left). SEM, scanning electron microscope; NFB, newly-formed bone; RG, residual graft; MS, marrow spaces.
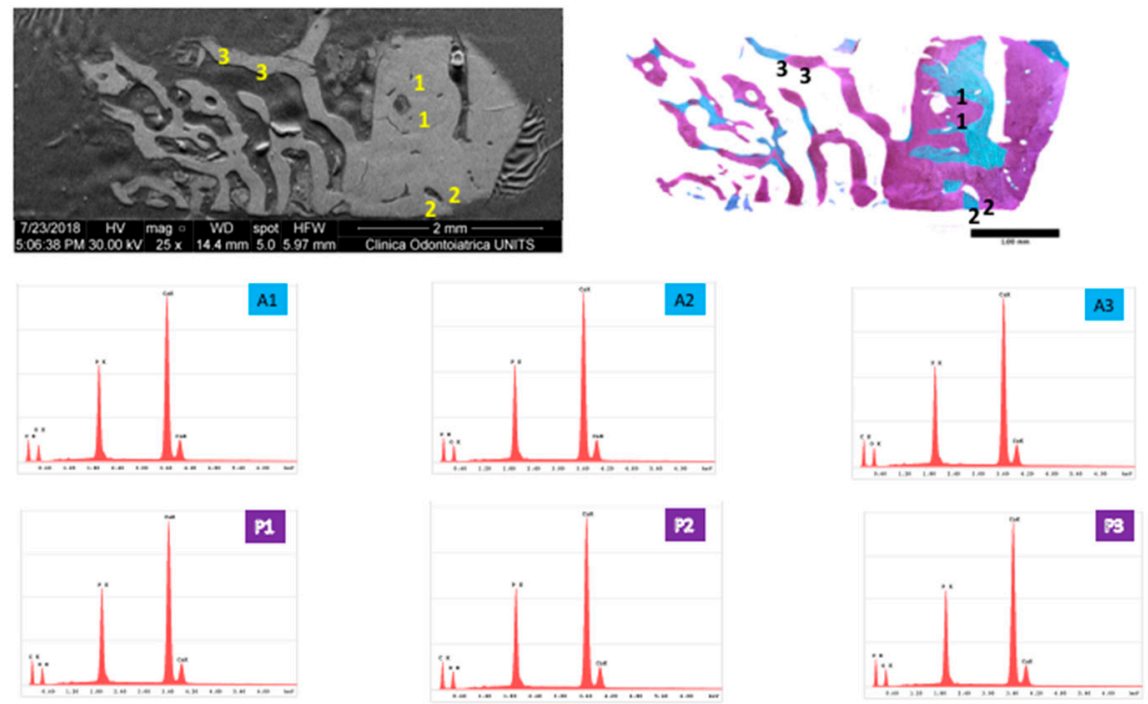

Figure 7. Upper left: detail of secondary electrons SEM image of the bone specimen with the numerical identification of the sites selected for EDX analysis; upper right: histological section stained with acid fuchsine-toluidine blue modified according to histomorphometric results to highlight NFB (Azure) and RG (purple) with correspondence of numerical reference for EDX examination; A1, A2, A3: EDX analysis for NFB; P1, P2, P3: EDX analysis for RG. SEM, scanning electron microscope; EDX, Energy Dispersive X-ray; NFB, newly-formed bone; RG, residual graft. 


\section{Discussion}

Allogeneic fresh frozen bone (FFB) has been widely used for years in orthopedic reconstructive surgery and reported to have different successful applications in the oral and maxillofacial district, including ridge augmentation [29-32], reconstruction of large post-traumatic or post-oncologic defects [33-35], and sinus floor elevation [36-40]. FFB is osteoconductive and weakly osteoinductive, and its main advantages compared to the autogenous bone are its unlimited availability coupled with the lower morbidity for the patient, with no necessity of second surgical site to harvest the graft. Main concerns related to the use of FFB, even if remote, are the possible risks of cross-infection $[41,42]$ and immune response complications [43,44].

The current study reported, for the first time, histomorphometric and SEM analyses performed on a bone specimen harvested 15 years after maxillary sinus augmentation with FFB block. The main interest of these results is represented by the exceptional duration of the follow-up, allowing to evaluate the percentage of vital bone and residual FFB 15 years after the grafting procedure. Conversely, the availability of a single specimen expresses the weakness of the present results; thus careful conclusions should be drawn.

The biopsy analyzed in the current investigation showed 15.4\% residual graft particles (RG). This finding is in agreement with a recent study of Deluiz et al. [45], in which biopsies from ridges augmented with FFB blocks were retrieved four (24.3\% RG) and six months (18.4\% RG) after grafting. These data, even if they should be interpreted with caution, seem to indicate that the greatest part of graft remodeling and resorption takes place in the first period after the surgical procedure, likely as a consequence of the healing process. Then, after a second possible biological boost for the remodeling process given by the second surgical trauma (implant placement), no further modifications in terms of graft resorption seem to occur over time. Moreover, the absence of osteoclasts in our specimen is indicative of a bone site with low turnover. However, no inflammatory cells or infiltrate were detected, suggesting a good integration of FFB, which appeared well integrated with the newly-formed bone (NFB) without discontinuities between the two components under optical and scanning electron microscopy. Only different staining affinity and electron uptake (together with the presence of empty osteocytic lacunae) revealed their origin.

In recent systematic reviews $[46,47]$, autogenous bone $(\mathrm{AB})$, when used as a grafting material in the maxillary sinus, promote the highest percentage of NFB in comparison to the other bone substitutes. However, implants placed into sinuses grafted with $\mathrm{AB}$ exhibited a lower survival rate compared to sinuses grafted with other bone substitutes. This finding has been attributed to the $\mathrm{AB}$ high resorption rate. Shanbhag and coworkers confirmed that $A B$ presents one of the greatest volumetric contraction among the various bone substitutes, followed by allografts [48]. According to the different formulations of allograft (demineralized freeze-dried bone allograft, mineralized freeze-dried bone allograft or FFB), different behaviors in the maxillary sinus have been reported, probably with higher resorption rate and lower volumetric stability for demineralized allografts, even if associated with an increased osteoinductive potential related to the direct effect of growth factors [49,50]. FFB blocks were associated with satisfactory volumetric bone maintenance, even in more challenging regenerative procedures, such as posterior mandible augmentation [51].

EDX analysis allowed us to estimate the chemical composition of the two bone compartments (NFB and RG). Apparently, even if non-vital, RG particles resulted comparable with NFB in terms of $\mathrm{Ca}++$ and $\mathrm{P}++$ contents. This finding confirmed that the laboratory processing, to whom FFB is subjected for its preparation, do not alter the chemical and morphological structure of its mineral portion, while bone proteins are subjected to morphologic and functional alterations related to heat and freezing cycles [52]. Another aspect to be taken into consideration during the operative and preoperative phase surely is represented by the surgical difficulties and by all the complications that this intervention can represent. We must also remember that the result of an advanced surgical technique depends strictly on biomaterials, as well as on the success of the surgical procedure. Some intraoperative aspects should be evaluated in advance, such as the presence of bony spines or of 
septa within the maxillary sinus, which can make the sinus membrane detachment procedure more difficult. Alternatively, the presence of anomalies on the membrane itself, such as hypertrophy or the presence of an abnormal vascularization or the presence of an antral artery, makes intervention difficult. In this case, the vessels should be isolated very carefully to prevent intraoperative hemorrhage [53-55]. The use of grafting materials in surgical techniques, as we saw in the course of the study, is, therefore, a current topic and widely used in the different fields of oral surgery [56-58]. We must also consider the biomaterials that are used in the regeneration phase; for example, depending on the type of graft material, we have different characteristics, such as osteoconductivity, osteoinductivity, and osteogenicity. It is also possible to create mixtures of materials using either autologous bone or growth or hormonal factors, such as PRF or CGF (Platelet Rich Fibrin or Concentrated Growth Factor). This improves tissue response by mixing the capabilities and characteristics of one biomaterial with another [59-61]. The possible contamination of the materials or even the post-surgical resorption of the latter can make implant-prosthetic rehabilitation less predictable, exposing the implant fixtures to a risk of peri-implant disease [62], leading to acute and then chronic inflammatory processes that could lead to failure if not treated [63].

\section{Conclusions}

The histologic observations of the present study demonstrated a perfect integration between newly-formed bone and fresh frozen allograft, whose remnants are still present and detectable $(15 \%$ of the biopsy volume) fifteen years after the grafting procedure. Further clinical investigations should confirm these data and highlight possible differences in remodeling and degradation rate among various formulations of the same biomaterial (cortico-cancellous block vs. chips), with particular attention to long-term modifications. Previously, different studies in the literature have been examined in depth, and many studies have carried out analyses using enlargement methods (SEM) as in our article. The literature and the results are in agreement with what can be inferred from our histomorphometric analysis. In any case, the maxillary sinus lift method has become a much more predictable and safe technique, thanks to the advent of new biomaterials and to the improvement of surgical techniques. We must remember that the aim of the sinus lift is always to allow a correct occlusal rehabilitation through the supported implants prostheses, and therefore the dental materials used also play an important role in implant survival and tissue stability.

Author Contributions: Conceptualization, C.S. and T.L.; methodology, F.B.; data curation, V.N.; writing-original draft preparation, C.S.; writing-review and editing, M.C.; visualization, L.F.; supervision, R.D.

Funding: This research received no external funding.

Conflicts of Interest: The authors declare no conflict of interest.

\section{References}

1. Boyne, P.J.; James, R.A. Grafting of the maxillary sinus floor with autogenous marrow and bone. J. Oral Surg. 1980, 38, 613-616. [PubMed]

2. Tatum, H., Jr. Maxillary and sinus implant reconstructions. Dent. Clin. N. Am. 1986, 30, 207-229.

3. Stacchi, C.; Vercellotti, T.; Toschetti, A.; Speroni, S.; Salgarello, S.; Di Lenarda, R. Intraoperative complications during sinus floor elevation using two different ultrasonic approaches: A two-center, randomized, controlled clinical trial. Clin. Implant Dent. Relat. Res. 2015, 17 (Suppl. 1), e117-e125. [CrossRef] [PubMed]

4. Stacchi, C.; Andolsek, F.; Berton, F.; Perinetti, G.; Navarra, C.O.; Di Lenarda, R. Intraoperative Complications During Sinus Floor Elevation with Lateral Approach: A Systematic Review. Int. J. Oral Maxillofac. Implants 2017, 32, e107-e118. [CrossRef] [PubMed]

5. Stacchi, C.; Lombardi, T.; Cusimano, P.; Berton, F.; Lauritano, F.; Cervino, G.; Di Lenarda, R.; Cicciù, M. Bone Scrapers Versus Piezoelectric Surgery in the Lateral Antrostomy for Sinus Floor Elevation. J. Craniofac. Surg. 2017, 28, 1191-1196. [CrossRef] 
6. Stacchi, C.; Lombardi, T.; Ottonelli, R.; Berton, F.; Perinetti, G.; Traini, T. New bone formation after transcrestal sinus floor elevation was influenced by sinus cavity dimensions: A prospective histologic and histomorphometric study. Clin. Oral Implants Res. 2018, 29, 465-479. [CrossRef]

7. Thoma, D.S.; Cha, J.K.; Jung, U.W. Treatment concepts for the posterior maxilla and mandible: Short implants versus long implants in augmented bone. J. Periodontal Implant Sci. 2017, 47, 2-12. [CrossRef] [PubMed]

8. Ravidà, A.; Wang, I.C.; Barootchi, S.; Askar, H.; Tavelli, L.; Gargallo-Albiol, J.; Wang, H.L. Meta-analysis of randomized clinical trials comparing clinical and patient-reported outcomes between extra-short $(\leq 6 \mathrm{~mm})$ and longer ( $\geq 10 \mathrm{~mm}$ ) implants. J. Clin. Periodontol. 2019, 46, 118-142. [CrossRef] [PubMed]

9. Stacchi, C.; Orsini, G.; Di Iorio, D.; Breschi, L.; Di Lenarda, R. Clinical, histologic, and histomorphometric analyses of regenerated bone in maxillary sinus augmentation using fresh frozen human bone allografts. J. Periodontol. 2008, 79, 1789-1796. [CrossRef] [PubMed]

10. Laino, L.; Troiano, G.; Giannatempo, G.; Graziani, U.; Ciavarella, D.; Dioguardi, M.; Lo Muzio, L.; Lauritano, F.; Cicciù, M. Sinus Lift Augmentation by Using Calcium Sulphate. A Retrospective 12 Months Radiographic Evaluation Over 25 Treated Italian Patients. Open Dent. J. 2015, 9, 414-419. [CrossRef] [PubMed]

11. Starch-Jensen, T.; Schou, S. Maxillary Sinus Membrane Elevation with Simultaneous Installation of Implants Without the Use of a Graft Material: A Systematic Review. Implant Dent. 2017, 26, 621-633. [CrossRef]

12. Starch-Jensen, T.; Mordenfeld, A.; Becktor, J.P.; Jensen, S.S. Maxillary Sinus Floor Augmentation with Synthetic Bone Substitutes Compared with Other Grafting Materials: A Systematic Review and Meta-analysis. Implant Dent. 2018, 27, 363-374. [CrossRef]

13. Turco, G.; Porrelli, D.; Marsich, E.; Vecchies, F.; Lombardi, T.; Stacchi, C.; Di Lenarda, R. Three-Dimensional Bone Substitutes for Oral and Maxillofacial Surgery: Biological and Structural Characterization. J. Funct. Biomater. 2018, 9, 62. [CrossRef]

14. Cicciù, M.; Cervino, G.; Herford, A.S.; Famà, F.; Bramanti, E.; Fiorillo, L.; Lauritano, F.; Sambataro, S.; Troiano, G.; Laino, L. Facial Bone Reconstruction Using both Marine or Non-Marine Bone Substitutes: Evaluation of Current Outcomes in a Systematic Literature Review. Mar. Drugs 2018, 16, 27. [CrossRef]

15. Busenlechner, D.; Huber, C.D.; Vasak, C.; Dobsak, A.; Gruber, R.; Watzek, G. Sinus augmentation analysis revised: The gradient of graft consolidation. Clin. Oral Implants Res. 2009, 20, 1078-1083. [CrossRef]

16. Avila, G.; Wang, H.L.; Galindo-Moreno, P.; Misch, C.E.; Bagramian, R.A.; Rudek, I.; Benavides, E.; Moreno-Riestra, I.; Braun, T.; Neiva, R. The influence of the bucco-palatal distance on sinus augmentation outcomes. J. Periodontol. 2010, 81, 1041-1050. [CrossRef]

17. Soardi, C.M.; Spinato, S.; Zaffe, D.; Wang, H.L. Atrophic maxillary floor augmentation by mineralized human bone allograft in sinuses of different size: An histologic and histomorphometric analysis. Clin. Oral Implants Res. 2011, 22, 560-566. [CrossRef]

18. Spinato, S.; Bernardello, F.; Galindo-Moreno, P.; Zaffe, D. Maxillary sinus augmentation by crestal access: A retrospective study on cavity size and outcome correlation. Clin. Oral Implants Res. 2015, 26, 1375-1382. [CrossRef]

19. Monje, A.; Catena, A.; Monje, F.; Gonzalez-García, R.; Galindo-Moreno, P.; Suarez, F.; Wang, H.L. Maxillary sinus lateral wall thickness and morphologic patterns in the atrophic posterior maxilla. J. Periodontol. 2014, 85, 676-682. [CrossRef]

20. Lombardi, T.; Stacchi, C.; Berton, F.; Traini, T.; Torelli, L.; Di Lenarda, R. Influence of Maxillary Sinus Width on New Bone Formation After Transcrestal Sinus Floor Elevation: A Proof-of-Concept Prospective Cohort Study. Implant Dent. 2017, 26, 209-216. [CrossRef]

21. Pardiñas López, S.; Froum, S.; Khouly, I. Histomorphometric Analysis of a Biopsy Harvested 10 Years after Maxillary Sinus Augmentation with Anorganic Bovine Bone Matrix and Plasma Rich in Growth Factors: A Case Report. Implant Dent. 2015, 24, 480-486. [CrossRef]

22. Ayna, M.; Açil, Y.; Gulses, A. Fate of a Bovine-Derived Xenograft in Maxillary Sinus Floor Elevation after 14 Years: Histologic and Radiologic Analysis. Int. J. Periodontics Restorative Dent. 2015, 35, 541-547. [CrossRef] [PubMed]

23. Mordenfeld, A.; Hallman, M.; Johansson, C.B.; Albrektsson, T. Histological and histomorphometrical analyses of biopsies harvested 11 years after maxillary sinus floor augmentation with deproteinized bovine and autogenous bone. Clin. Oral Implants Res. 2010, 21, 961-970. [CrossRef] 
24. Galindo-Moreno, P.; Hernández-Cortés, P.; Mesa, F.; Carranza, N.; Juodzbalys, G.; Aguilar, M.; O’Valle, F. Slow resorption of anorganic bovine bone by osteoclasts in maxillary sinus augmentation. Clin. Implant Dent. Relat. Res. 2013, 15, 858-866. [CrossRef]

25. Di Stefano, D.A.; Gastaldi, G.; Vinci, R.; Polizzi, E.M.; Cinci, L.; Pieri, L.; Gherlone, E. Bone Formation Following Sinus Augmentation with an Equine-Derived Bone Graft: A Retrospective Histologic and Histomorphometric Study with 36-Month Follow-up. Int. J. Oral Maxillofac. Implants 2016, 31, $406-412$. [CrossRef]

26. Sentineri, R.; Lombardi, T.; Berton, F.; Stacchi, C. Laurell-Gottlow suture modified by Sentineri for tight closure of a wound with a single line of sutures. Br. J. Oral Maxillofac. Surg. 2016, 54, e18-e19. [CrossRef] [PubMed]

27. Lebeau, A.; Muthmann, H.; Sendelhofert, A.; Diebold, J.; Löhrs, U. Histochemistry and Immunohistochemistry on Bone Marrow Biopsies: A Rapid Procedure for Methyl Methacrylate Pathology. Res. Pract. 1995, 191, 121-129. [CrossRef]

28. Cervino, G.; Fiorillo, L.; Spagnuolo, G.; Bramanti, E.; Laino, L.; Lauritano, F.; Cicciù, M. Interface Between MTA and Dental Bonding Agents: Scanning Electron Microscope Evaluation. J. Int. Soc. Prev. Community Dent. 2017, 7, 64-68. [CrossRef] [PubMed]

29. Carinci, F.; Brunelli, G.; Zollino, I.; Franco, M.; Viscioni, A.; Rigo, L.; Guidi, R.; Strohmenger, L. Mandibles grafted with fresh-frozen bone: An evaluation of implant outcome. Implant Dent. 2009, 18, 86-95. [CrossRef]

30. Orsini, G.; Stacchi, C.; Visintini, E.; Di Iorio, D.; Putignano, A.; Breschi, L.; Di Lenarda, R. Clinical and histologic evaluation of fresh frozen human bone grafts for horizontal reconstruction of maxillary alveolar ridges. Int. J. Periodontics Restor. Dent. 2011, 31, 535-544.

31. Silva, E.R.; Ferraz, E.P.; Neto, E.C.; Chaushu, G.; Chaushu, L.; Xavier, S.P. Volumetric Stability of Fresh Frozen Bone Blocks in Atrophic Posterior Mandible Augmentation. J. Oral Implantol. 2017, 43, 25-32. [CrossRef]

32. Dias, R.R.; Sehn, F.P.; de Santana Santos, T.; Silva, E.R.; Chaushu, G.; Xavier, S.P. Corticocancellous fresh-frozen allograft bone blocks for augmenting atrophied posterior mandibles in humans. Clin. Oral Implants Res. 2016, 27, 39-46. [CrossRef] [PubMed]

33. Chen, S.Y.; Liu, Z.H.; Lu, Y.; Hu, Y.J. Application of autologous bone fresh-frozen and re-implantation in treatment of cranio-maxillofacial bone tumors: Report of 4 cases. Shanghai Kou Qiang Yi Xue 2008, 17, 545-547.

34. Albanese, M.; Procacci, P.; Sancassani, G.; Nocini, P.F. Fresh-frozen human bone graft to repair defect after mandibular giant follicular cyst removal: A case report. Cell Tissue Bank. 2012, 13, 305-313. [CrossRef] [PubMed]

35. Bucci, T.; Nocini, P.F. Functional Reconstruction of Nonsegmental Mandibular Defect with Fresh Frozen Bone Graft and Delayed Implants Placement. J. Craniofac. Surg. 2017, 28, 810-812. [CrossRef] [PubMed]

36. Rancitelli, D.; Borgonovo, A.E.; Cicciù, M.; Re, D.; Rizza, F.; Frigo, A.C.; Maiorana, C. Maxillary Sinus Septa and Anatomic Correlation with the Schneiderian Membrane. J. Craniofac. Surg. 2015, 26, 1394-1398. [CrossRef]

37. Acocella, A.; Bertolai, R.; Nissan, J.; Sacco, R. Clinical, histological and histomorphometrical study of maxillary sinus augmentation using cortico-cancellous fresh frozen bone chips. J. Craniomaxillofac. Surg. 2011, 39, 192-199. [CrossRef] [PubMed]

38. Viscioni, A.; Franco, M.; Paolin, A.; Cogliati, E.; Callegari, M.; Zollino, I.; Sollazzo, V.; Carinci, F. Effectiveness of fresh frozen and cryopreserved homologue iliac crest grafts used in sinus lifting: A comparative study. Cell Tissue Bank. 2011, 12, 263-271. [CrossRef]

39. De Castilho, T.R.; Tortamano, P.; Marotti, J.; de Andrade, J.C., Jr.; Chilvarquer, I.; Ximenez, M.E.; Alves, M.T. Clinical and Histomorphometric Evaluation of Fresh Frozen Bone Allograft in Sinus Lift Surgery. Clin. Implant Dent. Relat. Res. 2016, 18, 40-50. [CrossRef]

40. Xavier, S.P.; Dias, R.R.; Sehn, F.P.; Kahn, A.; Chaushu, L.; Chaushu, G. Maxillary sinus grafting with autograft vs. fresh frozen allograft: A split-mouth histomorphometric study. Clin. Oral Implants Res. 2015, 26, 1080-1085. [CrossRef]

41. Eastlund, T. Infectious disease transmission through cell, tissue, and organ transplantation: Reducing the risk through donor selection. Cell Transplant 1995, 4, 455-477. [CrossRef] [PubMed]

42. Lo Giudice, R.; Puleio, F.; Rizzo, D.; Alibrandi, A.; Lo Giudice, G.; Centofanti, A.; Fiorillo, L.; Di Mauro, D.; Nicita, F. Comparative Investigation of Cutting Devices on Bone Blocks: An SEM Morphological Analysis. Appl. Sci. 2019, 9, 351. [CrossRef] 
43. Aho, A.J.; Eskola, J.; Ekfors, T.; Manner, I.; Kouri, T.; Hollmen, T. Immune responses and clinical outcome of massive human osteoarticular allografts. Clin. Orthop. Relat. Res. 1998, 346, 196-206. [CrossRef]

44. Spin Neto, R.; Felipe Leite, C.; Pereira, L.A.; Marcantonio, E.; Marcantonio, E., Jr. Is peripheral blood cell balanced altered by the use of fresh frozen bone block allografts in lateral maxillary ridge augmentation? Clin. Implant Dent. Relat. Res. 2013, 15, 262-270. [CrossRef] [PubMed]

45. Deluiz, D.; Santos Oliveira, L.; Ramôa Pires, F.; Reiner, T.; Armada, L.; Nunes, M.A.; Muniz Barretto Tinoco, E. Incorporation and Remodeling of Bone Block Allografts in the Maxillary Reconstruction: A Randomized Clinical Trial. Clin. Implant Dent. Relat. Res. 2017, 19, 180-194. [CrossRef]

46. Danesh-Sani, S.A.; Engebretson, S.P.; Janal, M.N. Histomorphometric results of different grafting materials and effect of healing time on bone maturation after sinus floor augmentation: A systematic review and meta-analysis. J. Periodontal Res. 2017, 52, 301-312. [CrossRef] [PubMed]

47. Klijn, R.J.; Meijer, G.J.; Bronkhorst, E.M.; Jansen, J.A. A meta-analysis of histomorphometric results and graft healing time of various biomaterials compared to autologous bone used as sinus floor augmentation material in humans. Tissue Eng. Part B Rev. 2010, 16, 493-507. [CrossRef]

48. Shanbhag, S.; Shanbhag, V.; Stavropoulos, A. Volume changes of maxillary sinus augmentations over time: A systematic review. Int. J. Oral Maxillofac. Implants 2014, 29, 881-892. [CrossRef]

49. Sohn, D.S.; Bae, M.S.; Choi, B.J.; An, K.M.; Shin, H.I. Efficacy of demineralized bone matrix paste for maxillary sinus augmentation: A histologic and clinical study in humans. Oral Surg. Oral Med. Oral Pathol. Oral Radiol. Endod. 2009, 108, e30-e35. [CrossRef]

50. Schwartz, Z.; Mellonig, J.T.; Carnes, D.L., Jr.; de la Fontaine, J.; Cochran, D.L.; Dean, D.D.; Boyan, B.D. Ability of commercial demineralized freeze-dried bone allograft to induce new bone formation. J. Periodontol. 1996, 67, 918-926. [CrossRef]

51. Maridati, P.; Stoffella, E.; Speroni, S.; Cicciu, M.; Maiorana, C. Alveolar antral artery isolation during sinus lift procedure with the double window technique. Open Dent. J. 2014, 8, 95-103. [CrossRef] [PubMed]

52. Albert, A.; Leemrijse, T.; Druez, V.; Delloye, C.; Cornu, O. Are bone autografts still necessary in 2006? A three-year retrospective study of bone grafting. Acta Orthop. Belg. 2006, 72, 734-740. [PubMed]

53. Bernardi, S.; Mummolo, S.; Ciavarelli, L.M.; Li Vigni, M.; Continenza, M.A.; Marzo, G. Cone beam computed tomography investigation of the antral artery anastomosis in a population of Central Italy. Folia Morphol. 2016, 75, 149-153. [CrossRef] [PubMed]

54. Varela-Centelles, P.; Loira-Gago, M.; Gonzalez-Mosquera, A.; Seoane-Romero, J.M.; Garcia-Martin, J.M.; Seoane, J. Distance of the alveolar antral artery from the alveolar crest. Related factors and surgical considerations in sinus floor elevation. Med. Oral Patol. Oral Cir. Bucal 2016, 21, e758-e765. [CrossRef] [PubMed]

55. Favato, M.N.; Vidigal, B.C.; Cosso, M.G.; Manzi, F.R.; Shibli, J.A.; Zenóbio, E.G. Impact of human maxillary sinus volume on grafts dimensional changes used in maxillary sinus augmentation: A multislice tomographic study. Clin. Oral Implants Res. 2015, 26, 1450-1455. [CrossRef] [PubMed]

56. Poli, P.P.; Beretta, M.; Cicciù, M.; Maiorana, C. Alveolar ridge augmentation with titanium mesh. A retrospective clinical study. Open Dent. J. 2014, 8, 148-158. [CrossRef]

57. Herford, A.S.; Cicciù, M.; Eftimie, L.F.; Miller, M.; Signorino, F.; Famà, F.; Cervino, G.; Lo Giudice, G.; Bramanti, E.; Lauritano, F.; et al. rhBMP-2 applied as support of distraction osteogenesis: A split-mouth histological study over nonhuman primates mandibles. Int. J. Clin. Exp. Med. 2016, 9, 17187-17194.

58. Bramanti, E.; Matacena, G.; Cecchetti, F.; Arcuri, C.; Cicciù, M. Oral health-related quality of life in partially edentulous patients before and after implant therapy: A 2-year longitudinal study. Oral Implantol. 2013, 6, 37-42. [CrossRef]

59. Stähli, A.; Strauss, F.J.; Gruber, R. The use of platelet-rich plasma to enhance the outcomes of implant therapy: A systematic review. Clin. Oral Implants Res. 2018, 29 (Suppl. 18), 20-36. [CrossRef]

60. Lo Giudice, G.; Iannello, G.; Terranova, A.; Lo Giudice, R.; Pantaleo, G.; Cicciù, M. Transcrestal Sinus Lift Procedure Approaching Atrophic Maxillary Ridge: A 60-Month Clinical and Radiological Follow-Up Evaluation. Int. J. Dent. 2015, 2015, 261652. [CrossRef]

61. Abdalla, R.I.B.; Alqutaibi, A.Y.; Kaddah, A. Does the adjunctive use of platelet-rich plasma to bone graft during sinus augmentation reduce implant failure and complication? Systematic review and meta-analysis. Quintessence Int. 2018, 49, 139-146. [CrossRef] [PubMed] 
62. Matarese, G.; Ramaglia, L.; Fiorillo, L.; Cervino, G.; Lauritano, F.; Isola, G. Implantology and periodontal disease: The panacea to problem solving? Open Dent. J. 2017, 11, 460-465. [CrossRef] [PubMed]

63. Fiorillo, L.; Cervino, G.; Herford, A.S.; Lauritano, F.; D’Amico, C.; Lo Giudice, R.; Laino, L.; Troiano, G.; Crimi, S.; Cicciù, M. Interferon Crevicular Fluid Profile and Correlation with Periodontal Disease and Wound Healing: A Systemic Review of Recent Data. Int. J. Mol. Sci. 2018, 19, 1908. [CrossRef] [PubMed] 